Danzan Dabazhapovich Tsydenov

Tianzuo Institute of Architecture

Shenyang Jianzhu University

Shenyang, Liaoning, China

danzan23@yandex.ru

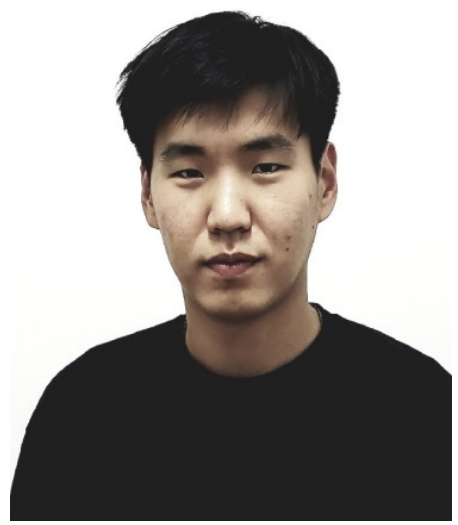

Co-author' Yuan Jingcheng. Tianzuo Institute of Architecture Shenyang Jianzhu

University

Shenyang, Liaoning, China

DOI 10.31554/978-5-7925-0571-1-2019-2-147-151

\title{
URBAN SPRAWL IN CENTRAL ASIA. COMPARING THE DEVELOPMENT OF THE SUBURBS OF BISHKEK, ULAANBAATAR, ULAN-UDE
}

In the post-socialist countries of Central Asia processes of urbanization and suburbanization for the last 30 years happened under the influence of new social, demographic and economic factors, not typical for well-studied countries of Europe and North America. The problems of spatial development of suburbs existing in this region have not been studied enough. The main goal of the article is analysis and comparison of modern problems in spatial development of suburban areas of agglomerations in Central Asia.

Keywords: cities, suburbs, Central Asia, urbanization, urban sprawl, suburbanization.

In the article we will consider the problems and features of suburbanization processes of three cities - Bishkek, Ulaanbaatar and Ulan-Ude. They are located in different countries of the region: Kyrgyzstan, Mongolia and Russia. For many years until the beginning of the 1990s, these cities developed in the conditions of total state regulation of economy and internal migration, limited opportunities for employment and shortage of housing for rural migrants. Culture of inhabitants of the region is traditionally close to each other and cities are in similar conditions of extreme continental cli- 
mate. These conditions give us a basis for comparison of development of suburbs in these cities.

Using open data from geographic information systems (GIS) (resources openstreetmaps, 2gis), official general plans and high-resolution satellite images of the LANDSAT program and superimposing them on each other, we were able to identify suburban and built-up areas. Using data for 1990 and 2016 and QGIS program, we compiled maps of the development of urban areas, which clearly shows the process of suburbanization. The image of Ulaanbaatar and the methodology are taken from [Cui 2018].

After analyzing situation in the cities of the Central Asia, we found that, despite significant economic and socio-demographic differences, the agglomerations of the region are going through a similar process of the chaotic growth of the city and the absorption of suburban settlements. Moreover, unlike the unauthorized development of the suburbs of Africa, South America and Asia, the development of the suburbs of Central Asia tends to be legalized as a result of electoral processes and inconsistent city management [Breslavsky 2017; Diener 2013; Hatcher 2015]

The architectural appearance of cities gains new shapes. The cities of Central Asia give impression of a big village. Most of the cities area is built up by fenced, primitive, low-rise buildings. They are made of the cheapest materials, without municipality-approved projects and fire protection documents. And because of the harsh climatic conditions buildings were built thoroughly and with clear intentions for further development [Mayer 2016].

Uncontrolled growth of urban agglomerations (Urban sprawl) in the region have already serious negative consequences:

- Environmental degradation - largely due to growing traffic and use of cheap fuel for heating non-energy-efficient buildings.

- Reduction of green spaces and agricultural land.

- Increased a road network and infrastructure construction costs. Spatial restriction of city development.

- Transport infrastructure that cannot withstand growing traffic.

- Difficulty in providing public transport for suburban areas. As a result, for many families in the suburbs, the need to have a car is often higher than the need for clean water.

- A general decline in the quality of life of residents of not only the suburbs, but also the city as a whole. 
Also, the study showed, even with a relatively insignificant increase in the city population, in the current conditions, the area occupied by the suburban territory increases disproportionately significantly, which is another evidence of an extremely inefficient administrative management.

According to some articles and my own observations, the majority of settled suburban residents who have been living there permanently for more than 5 years are generally satisfied with their housing. They form local communities and continue to invest earned money in their homes. At the same time, the residents of the suburbs are dissatisfied with the space surrounding them. This is due to the lack of social infrastructure (schools, kindergartens, sports fields), poor roads, dirty air, lack of green spaces, transport accessibility, garbage and crime. Moreover, most of the people living in the suburbs are attached to their homes, and are often interested in the development of the territories surrounding them [Breslavsky 2014; Park 2017].

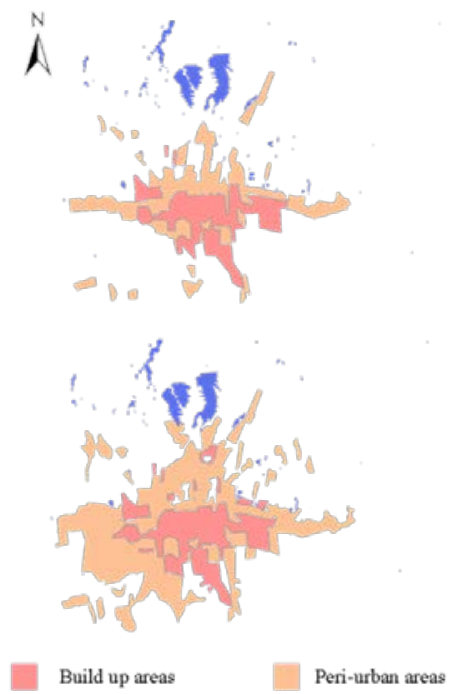

Fig. 1. Build-up areas and peri-urban areas of Bishkek in 1990 (top) and 2016 (bottom)

But, unfortunately, with the exception of the territories along the main transport routes, the development of communal and social services in the suburbs, under the existing economic conditions of the cities of the region, is 
difficult and often not economically effective in comparison with densely built-up territories. For example, the price of connecting to the central heating system of an individual house and its maintenance can be ten times higher than the price of connecting and maintenance of the apartment [ $\mathrm{Ka}$ mata 2010].

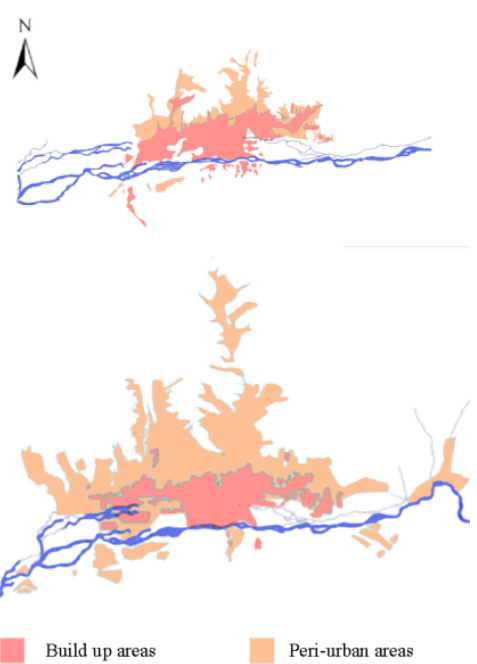

Fig. 2. Build-up areas and periurban areas of Ulaanbaatar in 1990 (top) and 2016 (bottom
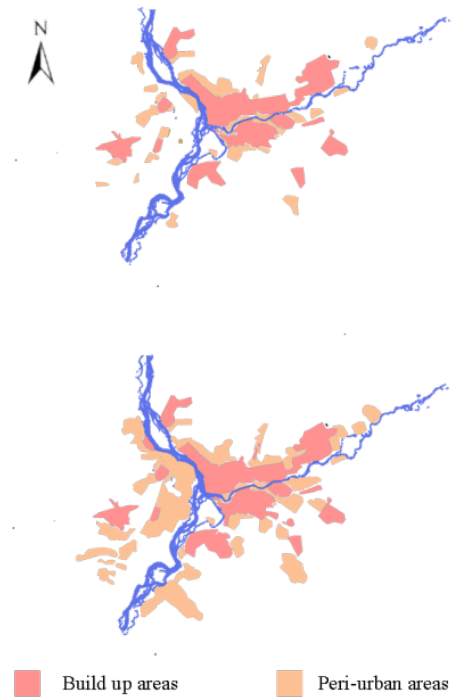

Fig. 3. Build-up areas and peri-urban areas of Ulan-Ude in 1990 (top) and 2016 (bottom)

Also, for many residents of houses built without permits, there are specific regional risks. In Bishkek, in the seismically active zone - many houses are made without projects and of clay materials, which is extremely dangerous [Flynn 2012]. In Ulaanbaatar, there are problems with dysentery and the disposal of household waste. In Ulan-Ude, some unauthorized buildings stand in a potentially flooded area.

It is worth noting, that not only among the residents of the suburbs, but often even among city managers, there is a lack of understanding of the principles of sustainable development of the city and the social harm of the suburban way of life [Byambadorj 2011].

It must be recognized that the existing suburbs of Central Asia and their problems will remain in this form for many years to come. But the agglo- 
merations of Central Asia should take measures to increase density and compactness of the built-up territories now. They should increase land use efficiency and assist migrants in developing a culture of urban life. City administrations need to abandon momentary decisions, and develop (and follow it) a long-term development strategy for the city and its suburbs, which meets the interests of the whole society. Otherwise, existing problems will only continue to worsen, and the more time passes, the more difficult it will be to solve them.

\section{References}

Breslavsky A. S. Nezaplanirovannye prigorody: sel'sko-gorodskaya migraciya i rost Ulan-Ude v postsovetskij period [Unplanned Suburbs: Rural-Urban Migration and the Growth of Ulan-Ude in the Post-Soviet Period] / ed. by M. Baldano. - UlanUde: Publishing House of the BSC SB RAS, 2014. - 192 p.

Breslavsky A. Prigorodnaya revolutsiya $\mathrm{v}$ regional'nom sreze (Ulan-Ude) ["Suburban Revolution": The regional case (Ulan-Ude)] // Russian Peasant Studies. - 2017. - Vol. 2, N. 1. - P. 90-101.

Byambadorj T., Amati M., Ruming K. J. Twenty first century nomadic city: Ger districts and barriers to the implementation of the Ulaanbaatar city master plan // Asia Pacific Viewpoint. - 2011. - Vol. 52(2). - P. 165-177.

Cui D., Wu D., Liu J., Xiao Y., Yembuu B., Adiya Z. Understanding urbanization and its impact on the livelihood levels of urban residents in Ulaanbaatar, Mongolia // Growth and Change. - 2019. - Vol. 50(2). - P. 745-774.

Diener A. C., Hagen J. City of felt and concrete: Negotiating cultural hybridity in Mongolia's capital of Ulaanbaatar // Nationalities Papers. - 2013. - Vol. 41(4). P. 622-650.

Flynn M., Kosmarskaya N. Exploring 'north' and 'south' in post-Soviet Bishkek: Discourses and perceptions of rural-urban migration // Nationalities Papers. 2012. - Vol. 40 (3). - P. 453-471.

Hatcher C. Illegal geographies of the state: The legalisation of a 'squatter' settlement in Bishkek, Kyrgyzstan // International Journal of Law in the Built Environment. - 2015. - Vol. 7(1). - P. 39-54.

Takuya K., Reichert J., Tsevegmid T., Kim Y., Sedgewick B. Managing urban expansion in Mongolia: best practices in scenario-based urban planning // World Bank. - 2010.

Park H., Fan P., John R., Chen J. Urbanization on the Mongolian Plateau after economic reform: Changes and causes // Applied Geography. - 2017. - Vol. 86. P. 118-127.

Mayer B. Climate migration and the politics of causal attribution: A case study in Mongolia // Migration \& Development. - 2016. Vol. 5(2). - P. 234-253. 